\title{
Evaluation of Modal and FEMA Pushover Procedures Using Strong-Motion Records of Buildings
}

\author{
Rakesh K. Goel, California Polytechnic State University, San Luis Obispo
}

The objective of this investigation is to evaluate the FEMA-356 Nonlinear Static Procedure (NSP) and a recently developed Modal Pushover Analysis (MPA) procedure using recorded motions of four buildings that were damaged during the 1994 Northridge earthquake. For this purpose, displacements and drifts from the FEMA-356 NSP and the MPA procedures are compared with the values "derived" from the recorded motions. It is found that the FEMA-356 NSP typically underestimates the drifts in upper stories and overestimates them in lower stories when compared to the recorded motions. Among the four FEMA-356 distributions considered, the "Uniform" distribution led to the most excessive underestimation or overestimation indicating that the need to carefully reevaluate the usefulness of this distribution in the FEMA-356 NSP. Furthermore, FEMA-356 distributions failed to provide accurate estimates of story drifts for a building that satisfied the FEMA-356 criterion for detecting the presence of higher mode effects indicating the need to carefully re-examine this criterion. The MPA procedure, in general, provides estimates of the response that are much closer to the values from the recorded motion compared to those from the FEMA-356 NSP. In particular, the MPA procedure, unlike the FEMA-356 NSP, is able to capture the effects of higher modes. For a building that exhibits dominant effects of "soft" first story, however, neither the MPA procedure nor the FEMA-356 NSP led to reasonable estimate of the response.

\section{INTRODUCTION}

Estimating seismic demands at low performance levels, such as life safety and collapse prevention, requires explicit consideration of inelastic behavior of the structure. While nonlinear response history analysis (RHA) is the most rigorous procedure to compute seismic demands, current civil engineering practice prefers to use the nonlinear static procedure (NSP) or pushover analysis. Although pushover analysis procedures have been proposed in several earlier documents (U.S. Army 1986, ATC 1996), the most commonly used pushover analysis is that specified in the FEMA-356 document (ASCE 2000). In early version of the FEMA NSP procedure (ATC 1997a, b), the seismic demands are computed by nonlinear static analysis of the structure subjected to monotonically increasing lateral forces with an invariant height-wise distribution until a predetermined target displacement is reached. Both the force distribution and target 
displacement are based on the assumption that the response is controlled by the fundamental mode and that the mode shape remains unchanged after the structure yields.

In past few years, several researchers have discussed the underlying assumptions and limitations of the pushover analysis (Elnashai 2001, Fajfar and Gaspersic 1996, Gupta and Krawinkler 1999, Maison and Bonowitz 1999, Reinhorn 1997, Skokan and Hart 2000). It has been found that satisfactory predictions of seismic demands are mostly restricted to low- and medium-rise structures for which higher mode effects are likely to be minimal and the inelastic action is distributed throughout the height of the structure (Krawinkler and Seneviratna 1998).

The FEMA documents also recognized the inability of the NSP in accurately predicting seismic demands of buildings with significant higher mode effects (ATC 1997b). Therefore, application of the NSP alone is restricted to building without higher mode effects. The NSP can be used for buildings with significant higher mode effects provided it is supplemented by the Linear Dynamic Procedure.

None of the invariant force distributions can account for redistribution of inertia forces because of structural yielding and the associated changes in the vibration properties of the structure. To overcome this limitation, several researchers have proposed adaptive force distributions that attempt to follow more closely the time-variant distributions of inertia forces (Bracci et al. 1997, Gupta and Kunnath 2000). The most recent version of the FEMA documents (ASCE 2000), denoted as FEMA-356, includes one adaptive distribution in the list of lateral load patterns from which two are selected (details are provided later). While these adaptive force distributions may provide better estimates of seismic demands (Gupta and Kunnath 2000), they are conceptually complicated, computationally demanding for routine application in structural engineering practice, and require special purpose computer programs to carry out the step-by-step analysis.

Attempts have also been made to consider more than the fundamental vibration mode in pushover analysis. The Multi-Mode Pushover (MMP) procedure (Paret et al. 1996, Sasaki et al. 1998) provided information on possible failure mechanisms due to higher modes, which may be missed by the standard NSP analyses. But other information of interest in the design process, such as story drifts and plastic rotations, could not be computed by the MMP procedure. The "sum-difference" method (Kunnath and Gupta 2000, Matsumori et al. 1999) also provided "useful" but limited information (Kunnath and Gupta 2000).

Recently, a modal pushover analysis (MPA) procedure has been developed based on structural dynamics theory that includes the contribution of several modes of vibration (Chopra and Goel 2002). This procedure was further refined and systematically evaluated using six buildings, each analyzed for 20 ground motions (Goel and Chopra 2004). The selected buildings represented two building heights-9-story and 20-story-and three different seismic regions of the United States: Boston, Seattle, and Los Angeles. The median value of story drifts obtained from the MPA procedure and nonlinear response history analysis (RHA) were compared. It was found that with sufficient number of "modes" included, the height-wise distribution of story drifts estimated by MPA is 
Table 1. Selected buildings, and peak ground and structure accelerations recorded during the 1994 Northridge earthquake

\begin{tabular}{lcccc}
\hline \hline & CSMIP Station & Number & & \multicolumn{2}{c}{ Peak Accelerations $(\mathrm{g})$} \\
\cline { 5 - 5 } Building Name & of Stories & Ground & Structure \\
\hline Van Nuys 7-Story & 24386 & 7 & 0.47 & 0.59 \\
Woodland Hills 13-Story & $\mathrm{C} 246$ & $13 / 1$ & 0.44 & 0.33 \\
Sherman Oaks 13-Story & 24322 & $13 / 2$ & 0.46 & 0.65 \\
Los Angeles 19-Story & 24643 & $19 / 4$ & 0.32 & 0.65 \\
\hline \hline
\end{tabular}

generally similar to trends noted from nonlinear RHA. Furthermore, the additional error (or bias) in the MPA procedure applied to inelastic structures is small to modest compared to the bias in response spectrum analysis (RSA) applied to elastic structures - the standard analytical tool for the structural engineering profession - unless the building is deformed into the inelastic region with significant stiffness and strength deterioration.

Most of the previous work on development and evaluation of the NSP and improved procedures are based on response of analytical models subjected to recorded and/or simulated earthquake ground motions. Recorded motions of buildings, especially those deformed into the inelastic range, provide a unique opportunity to evaluate such procedures. Therefore, the principal objective of this investigation is to evaluate the FEMA356 NSP and the MPA procedures using recorded motions of buildings that were deformed beyond the elastic limit during the 1994 Northridge earthquake.

\section{SELECTED BUILDINGS AND RECORDED MOTIONS}

Recorded motions of buildings that were deformed beyond the elastic limit (or damaged) during the earthquake are required for this investigation. For this purpose, four buildings have been identified (Table 1) for which the motions were recorded during the 1994 Northridge earthquake. Of these four buildings, three have been extensively instrumented by California Strong Motion Instrumentation Program (CSMIP) and one has been nominally instrumented in accordance to the code requirements. Following is a brief description of each of these buildings.

The Van Nuys 7-story reinforced concrete building was designed in 1965 and constructed in 1966. The vertical load carrying system consists of 8- to 10-inch (20.3 to 25 $\mathrm{cm})$ concrete flat-slabs supported by concrete columns and spandrel beams at the perimeter (Naeim 1997, 2000). The lateral load resisting system consists of interior columnslab frames and exterior column-spandrel beam frames.

This building is instrumented to measure horizontal accelerations at the ground, $2^{\text {nd }}$ floor, $3^{\text {rd }}$ floor, $6^{\text {th }}$ floor, and the roof (Figure 1). Although motions of this building have been recorded during several earthquakes in the past, the motions of interest in this investigation are the ones recorded during the 1994 Northridge earthquake. The peak horizontal accelerations recorded during this earthquake were 0.47 at the base and $0.59 \mathrm{~g}$ in 

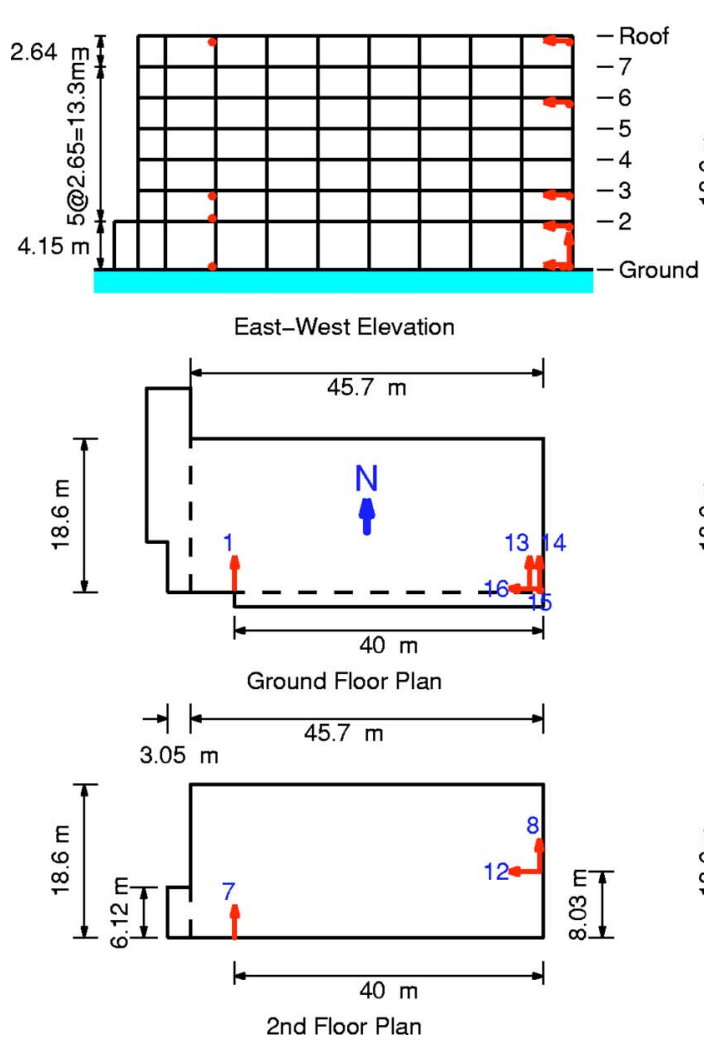

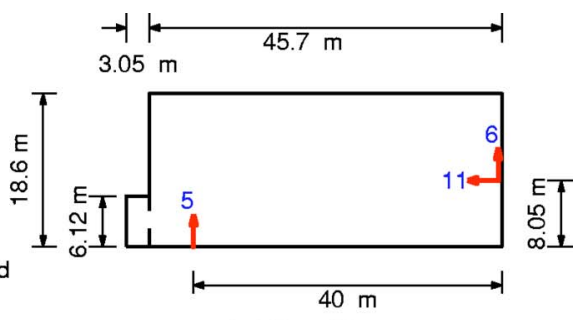

3rd Floor Plan

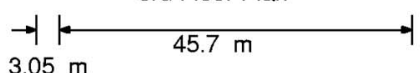

$3.05 \mathrm{~m}$
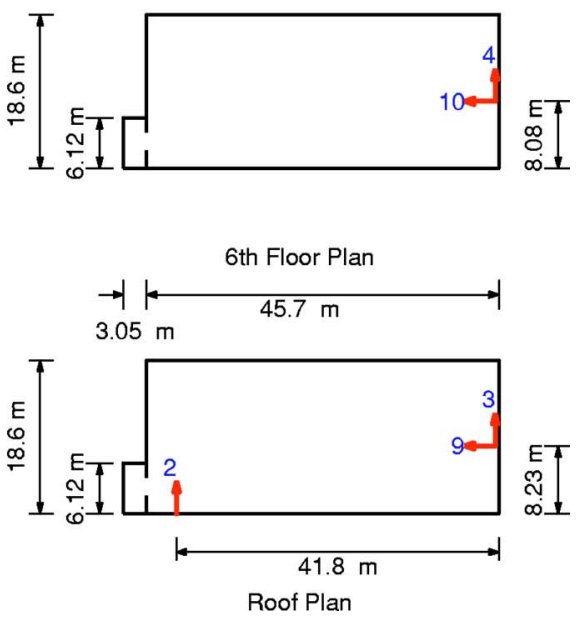

Figure 1. Sensor locations in Van Nuys 7-story building.

the structure. This building was heavily damaged during the 1994 Northridge earthquake and subsequently closed for repair and retrofit. Several columns between the fourth and fifth floors failed in shear at the top just below the spandrel beam. Most damage was observed in the longitudinal perimeter frames, with south perimeter suffering more damage than the north perimeter. This building has been extensively analyzed in the past (Goel et al. 2000; Islam et al. 1998; Li and Jirsa 1998; Naeim 1997, 2000).

The Woodland Hills 13-story welded special moment frame building was constructed in 1975. Its lateral load-resisting system consists of four identical steel frames along the building perimeter. The typical floor is square with $160-\mathrm{ft}(48.8-\mathrm{m})$ sides. At the first floor above ground, the plan broadens on three sides to form a plaza level, while the fourth side abuts a landscape berm. These conditions provide a high degree of lateral restraint at this level. Basement perimeter walls are reinforced concrete and the foundation system consists of piles, pilecaps, and grade beams.

The Woodland Hills building is nominally instrumented as required by the local building code (Figure 2). Motions were recorded during the 1994 Northridge earthquake at three levels: ground, $6^{\text {th }}$ floor, and $12^{\text {th }}$ floor (Darragh et al. 1994). The peak horizontal 

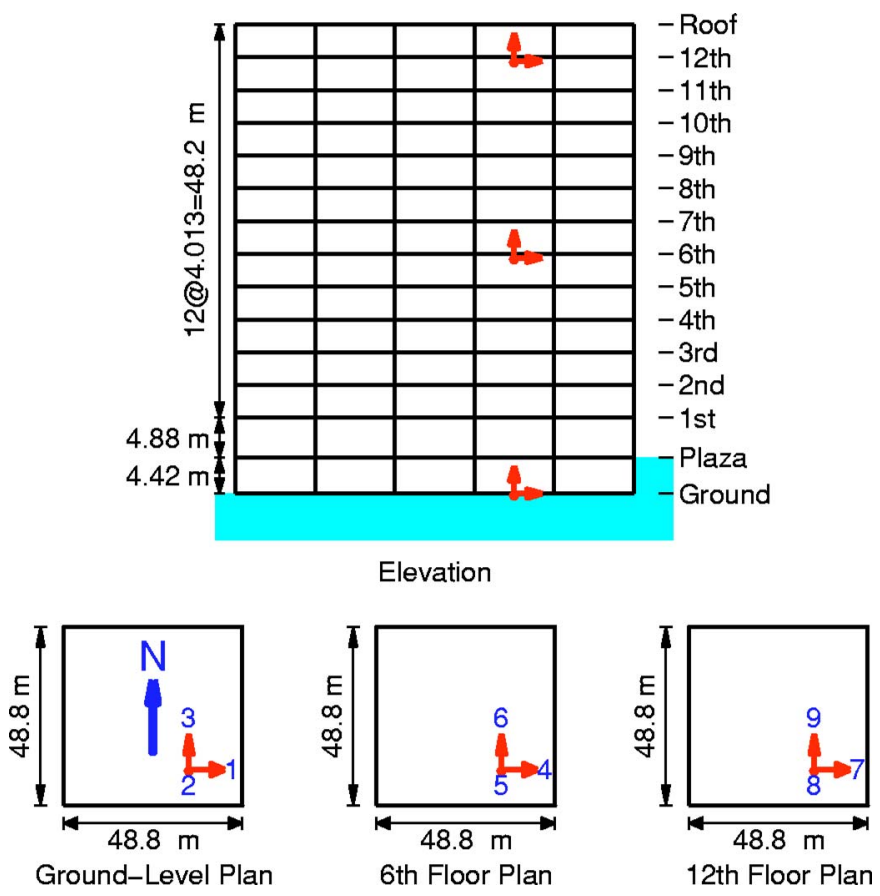

Figure 2. Sensor location in Woodland Hills 13-story building.

accelerations were $0.44 \mathrm{~g}$ at the base and $0.33 \mathrm{~g}$ in the structure. Damage to this building during the 1994 Northridge earthquake consisted of local fracture at the beam-to-column welded joints (Uang et al. 1997).

The Sherman Oaks building has 13 stories above and two floors below the ground. Designed in 1964, its vertical load carrying system consists of 4.5-inch (11.4-cm) thick oneway slabs supported by concrete beams, girders, and columns. The lateral load system consists of moment-resisting concrete frames in the upper stories and concrete shear walls in the basements. The foundation system consists of concrete piles.

The Sherman Oaks building is instrumented to measure horizontal accelerations at the $2^{\text {nd }}$ sub-basement level, ground level, $2^{\text {nd }}$ floor, $8^{\text {th }}$ floor, and roof level (Figure 3 ). The peak horizontal accelerations recorded during the 1994 Northridge earthquake were $0.46 \mathrm{~g}$ at the basement and $0.65 \mathrm{~g}$ in the structure. The building is reported to have suffered cracks at many beam-column joints (Shakal et al. 1994).

The Los Angeles building has 19 stories above the ground level and 4 stories of parking below the ground level. The building was designed in 1966-67 and constructed in 1967. The vertical load carrying system consists of 4.5-in. (11.4-cm) thick reinforced concrete slabs supported on steel frames. The lateral load-resisting system consists of four moment-resisting steel frames in the longitudinal direction, and five X-braced steel frames in the transverse direction. The foundation system consists of 72-ft 4-in (22-m) 

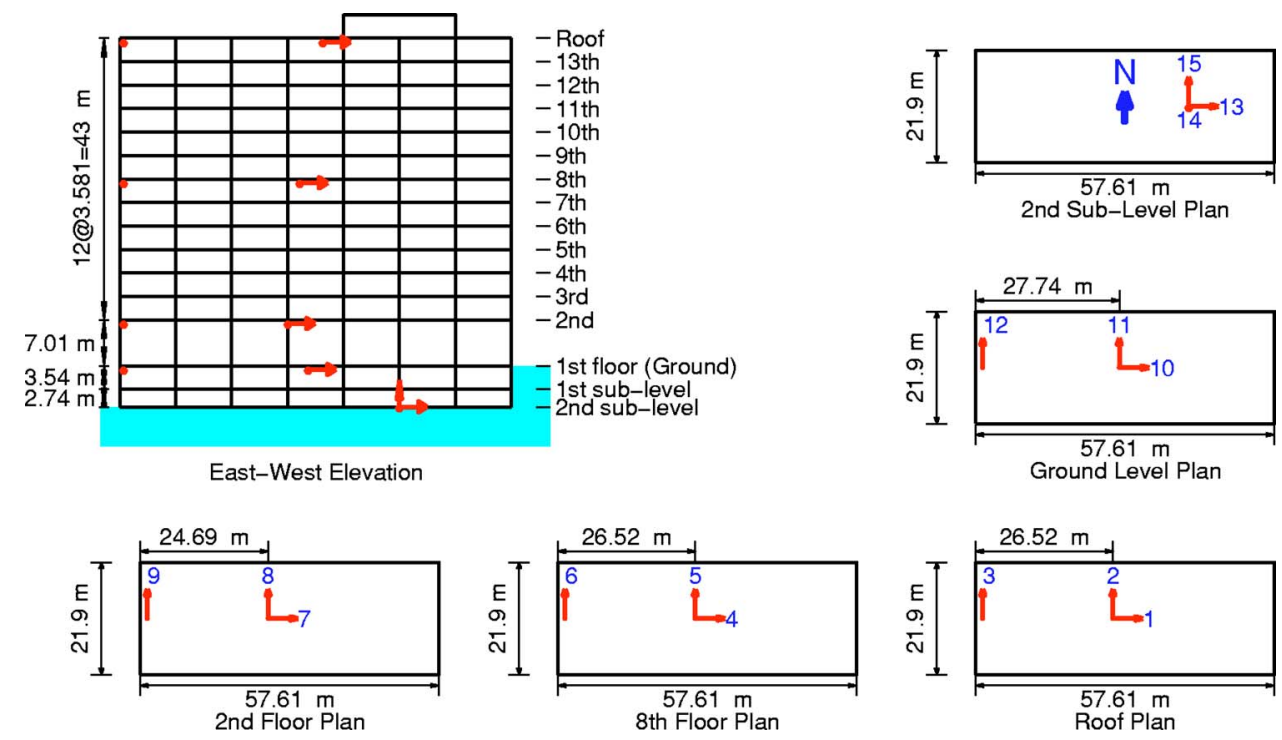

Figure 3. Sensor location in Sherman Oaks 13-story building.

long driven-steel I-beam piles (Hart 1973, Naeim 1998). The piles are capped in groups of three to ten with pile caps varying in thickness from $3 \mathrm{ft} 8$ in $(1.12 \mathrm{~m})$ to $5 \mathrm{ft} 8 \mathrm{in}$ $(1.73 \mathrm{~m})$. All pile caps are connected with $2 \mathrm{ft}$ by $2 \mathrm{ft}(0.61 \mathrm{~m}$ by $0.61 \mathrm{~m})$ reinforced concrete tie beams. The subsurface soil conditions are generally fine sand throughout the depth of the piles (Hart 1973).

This building is instrumented with 15 sensors to measure accelerations at the D subbasement level, $1^{\text {st }}$ floor, $2^{\text {nd }}$ floor, $8^{\text {th }}$ floor, and roof level (Figure 4$)$. The peak horizontal accelerations recorded during the 1994 Northridge earthquake were $0.32 \mathrm{~g}$ at the basement, $0.53 \mathrm{~g}$ at the ground floor, and $0.65 \mathrm{~g}$ at the roof. The building is reported to have suffered moderate damage in the form of buckling in some braces at upper floor levels (Naeim 1997).

\section{ANALYSIS OF RECORDED MOTIONS}

\section{“DERIVED” DISPLACEMENTS AND DRIFTS}

Since buildings are typically instrumented at a limited number of floors, the motions of non-instrumented floors must be inferred from the instrumented floors for calculations of interstory drifts in all stories. For this purpose, cubic spline interpolation procedure (De la Llera and Chopra 1998, Naeim 1997) is used. The cubic spline interpolation procedure is preferred over the parametric model procedure because it automatically accounts for nonlinearities and time variance of the building parameters. This procedure has been tested (De la Llera and Chopra 1998) and found to be highly accurate in estimating the motions of non-instrumented floors. 

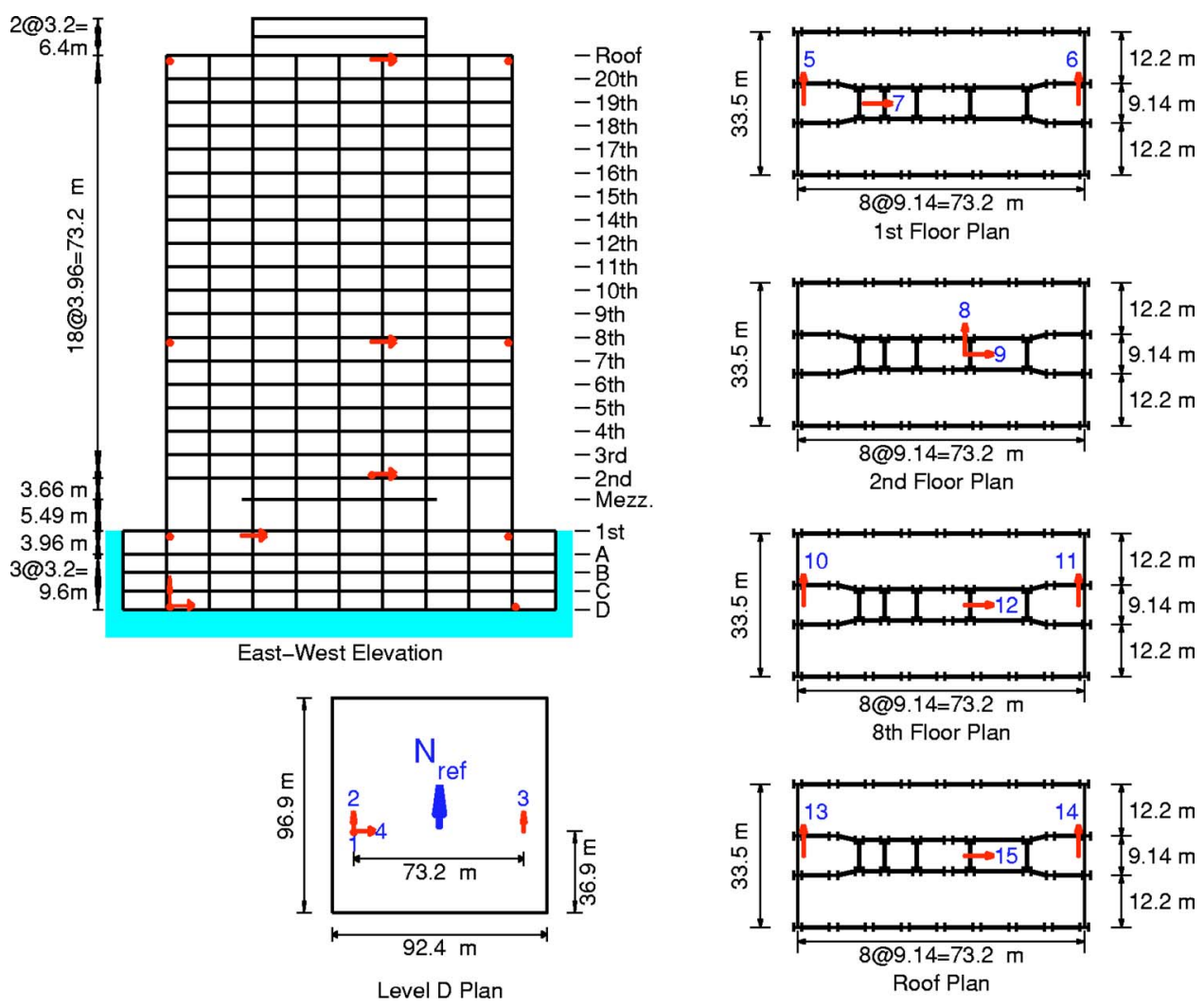

Figure 4. Sensor location in Los Angeles 19-story building.

The cubic spline interpolation is performed on the building deformation (relative to the base) instead of the floor accelerations as traditionally done. This is because splines satisfy conditions of continuity and differentiability of a second order at the interpolation points (i.e., instrumented floors in this case) and hence provide smooth shapes, as it should be, for the displacement field of the building.

Once the time variation of deformations of all floors have been developed using the cubic spline interpolation procedure, interstory drifts at each time instant is computed from

$$
\delta_{j}(t)=u_{j}(t)-u_{j-1}(t)
$$

in which $\delta_{j}(t)$ is the interstory drift in the $j$ th story, and $u_{j}(t)$ and $u_{j-1}(t)$ are the deformations at the $j$ th and $j-1$ th floor levels at time t. Once the time histories of the interstory drifts have been developed, peak values in the $j$ th story, $\delta_{j o}$, is computed as the absolute maximum value over time. These values, denoted as "derived" interstory drifts, along with the peak floor displacements, would be used to evaluate the FEMA-356 NSP and MPA procedures. 


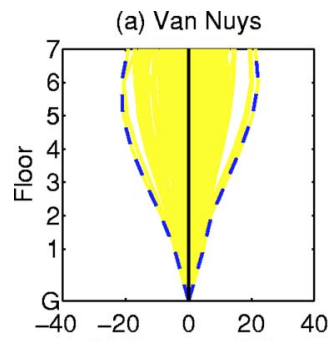

(b) Woodland Hills
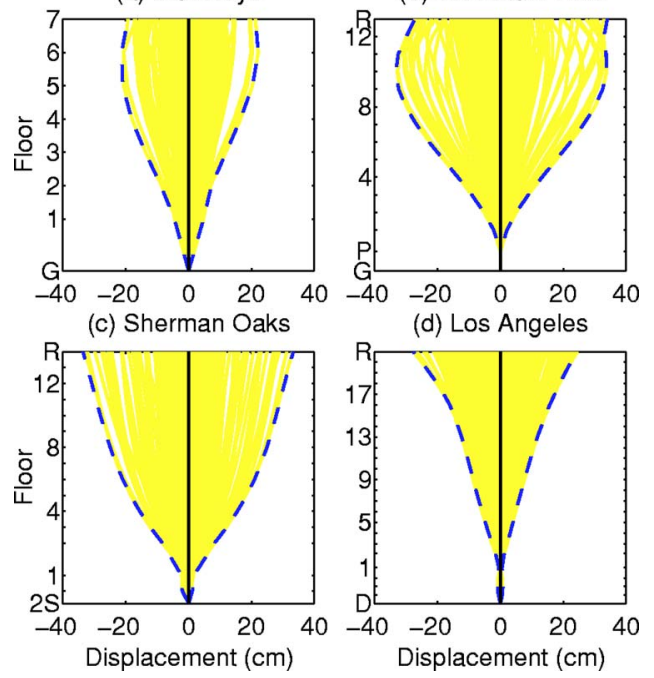

Figure 5. History of displacement profile for the selected buildings: solid light lines show the history of displacement profile, and dashed dark lines show the envelopes.

\section{DISPLACEMENT AND DRIFT PROFILE HISTORIES}

Histories of floor displacements and interstory drifts at geometric center of the building were "derived" using the aforementioned cubic spline interpolation procedure for each of the four selected buildings and are presented in Figures 5 and 6. The presented motions are in the east-west direction for the Van Nuys and Sherman Oaks buildings, and in the north-south direction for the Woodland Hills and Los Angeles buildings. The histories are plotted for the entire duration of the recorded motion at a time increment of $0.1 \mathrm{sec}$. Also included are the envelopes in the positive and negative directions.

The displacement profile results indicate that although the first-mode contribution is dominant, the second mode also contributes significantly. The second-mode contribution to floor displacements is especially noticeable for the Van Nuys and Woodland Hills buildings (Figures 5a and 5b), but less obvious for the Sherman Oaks and Los Angeles buildings (Figures $5 \mathrm{c}$ and $5 \mathrm{~d}$ ).

The story drift profiles of all buildings, however, exhibit significant contributions of higher modes. The contribution of second and higher modes is especially dominant in Van Nuys and Woodland Hills buildings (Figures $6 \mathrm{a}$ and 6b), while contribution of second mode is apparent in Los Angeles building (Figure 6d). The Sherman Oaks and Los Angeles buildings (Figures 6c and 6d) also exhibit significantly large drift in the first story (between levels 1 and 2); this is due to "soft" first story condition created by larger height of this story compared to the other stories in these buildings. The "soft" story effect is especially dominant for the Sherman Oaks building (Figure 6c). 
(a) Van Nuys

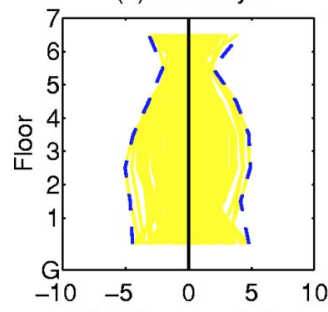

(c) Sherman Oaks

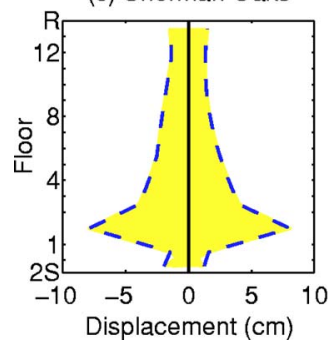

(b) Woodland Hills

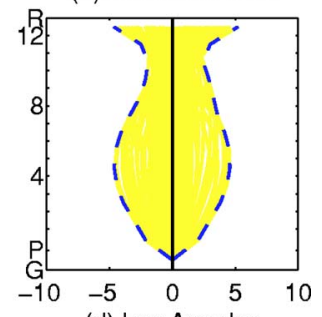

(d) Los Angeles

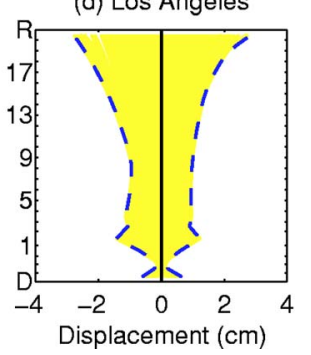

Figure 6. History of drift profile for the selected buildings: solid light lines show the history of displacement profile, and dashed dark lines show the envelopes.

\section{MODAL DECOMPOSITION OF RECORDED MOTIONS}

The contributions of various natural modes of vibration of the building to the total displacement can be extracted from the recorded (or "derived") motions by using the standard modal analysis method (Chopra 2001); the procedure would lead to exact modal contributions for buildings that remain elastic, but approximate for inelastic buildings. This procedure has been used previously (Chopra and Goel 2002) to investigate the contributions of higher modes in inelastic buildings.

The contribution of the $n$th mode to total deformation at floor level $j$ and time instant $t$ is given by

$$
u_{j n}(t)=\frac{\boldsymbol{\phi}_{n}^{T} \boldsymbol{m} \boldsymbol{u}(t)}{\boldsymbol{\phi}_{n}^{T} \boldsymbol{m} \boldsymbol{\phi}_{n}} \phi_{j n}
$$

in which $\boldsymbol{\phi}_{n}$ is the $n$th mode shape of the elastic building, $\boldsymbol{m}$ is the mass matrix, $\boldsymbol{u}(\mathrm{t})$ is the vector of displacements at all floor levels at time $t$, and $\phi_{j n}$ is the $n$ th-mode shape component at the $j$ th floor level. Once the contribution of the $n$th mode to the floor displacements have been computed, its contribution to interstory drift, $\delta_{j n}(t)$, can be computed using Equation 1.

\section{ANALYTICAL MODELS}

The computer program DRAIN-2DX (Prakash et al. 1993) was used for analysis of the selected buildings. The following procedure was used to calibrate the DRAIN-2DX analytical models against the information from the recorded motions. First, the model 
was calibrated by comparing the fundamental mode period from eigen analysis of the analytical model and the "elastic" period obtained from system-identification analysis. Second, the time histories of floor displacements and story drifts are computed from the analytical model using the acceleration recorded at the base as the input motion. The computed motions are then compared with the recorded motions to verify that the response from the analytical model correlates reasonably with the recorded motions. For the sake of brevity, the results are presented in this section only for floor displacements.

The analytical model of a building can only provide its "approximate" response because of several assumptions in the modeling procedure and errors in the numerical integration procedure. Therefore, matching computed response of an analytical model of a building with its "true" response from recorded motion is often not easy, especially if the building is deformed beyond its elastic limit. In this investigation, the analytical models were developed using standard engineering practice and readily available element models, without significant "massaging" of the model for the purpose of improving correlation between recorded and computed responses. Such a modeling approach may be appropriate for comparative evaluation of two analytical procedures - FEMA-356 NSP and MPA procedure - because of effects of modeling inaccuracies are present in both analytical procedures. Following is a brief description of the analytical models, their limitations, and comparison of the computed and recorded motions; additional details are available elsewhere (Goel 2003).

\section{VAN NUYS 7-STORY BUILDING}

The computer model used in earlier investigations (Browning et al. 2000, Goel et al. 2000) was refined to develop a model for the south frame of this building; this frame is of interest because it sustained significant damage during the 1994 Northridge earthquake. The frame is modeled using beam-columns elements with centerline dimensions. Initial stiffness was equal to 0.5 and 0.7 times the gross cross-sectional stiffness for beams and columns, respectively. The beams were modeled without P-M interaction, while P-M interaction relationship for reinforced concrete sections was used for the columns. The moment yield strengths were computed using conventional procedures (Browning et al. 2000). The mass equal to one-third of the total building mass was assigned to this frame, and Rayleigh damping of $10 \%$ was used for the first and third mode of vibration.

The displacement response history of the analytical model was calculated using the east-west component of the motion recorded at the base during the 1994 Northridge earthquake. The comparison of displacements from the response history analysis with

the recorded motions in the east-west direction at the center of the building, shown in Figure 7, indicates a reasonable, if not excellent, match between the two implying that the simple model used in this study is adequate. Results for story drifts (not presented) showed larger differences between recorded and computed motions compared to floor displacements - an observation consistent with the expectation that localized response such as story drift is more sensitive to modeling errors, especially for systems responding beyond the elastic limit.

It may be possible to further improve the accuracy of the model by using more ap- 

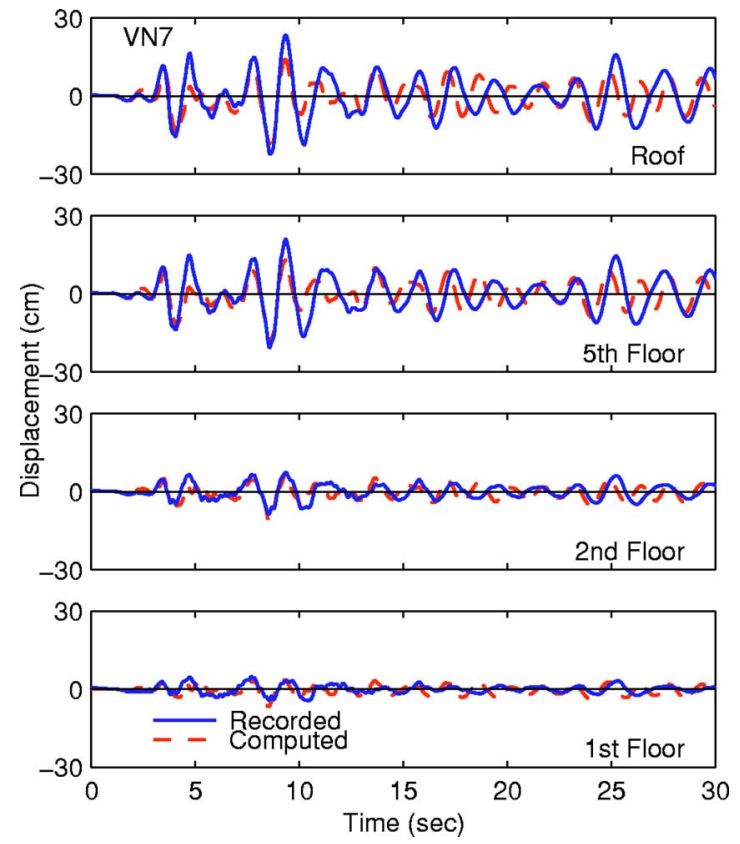

Figure 7. Comparison of displacements computed from analytical model with recorded displacements of the Van Nuys 7-story building.

propriate force-deformation relationships (Browning et al. 2000, Li and Jirsa 1998). The major limitations - all due to lack of appropriate elements in the computer program DRAIN-2DX - of the simple model used in this investigation are (1) the momentrotation relationship was defined by a bilinear curve with $3 \%$ strain-hardening; the realistic model should prescribe a failure limit on the rotations; (2) the shear-moment-axial interaction was ignored; this interaction may be important for reinforced concrete members; and (3) the shear-critical behavior of the columns was not explicitly modeled.

It must also be noted that the model used in this investigation, as well as those used by others (Browning et al. 2000, Li and Jirsa 1998), are two-dimensional in nature. There is strong evidence from recorded motions that this building exhibited significant torsional motions during the 1994 Northridge and other earthquakes. Therefore, only a three-dimensional model would be able to capture the true behavior of this building.

\section{WOODLAND HILLS 13-STORY BUILDING}

The computer model developed earlier (Uang et al. 1997) was used for analysis of this building. The moment frame in the north-south direction is modeled because it experienced significant damage, in the form of connection failures, during the 1994 Northridge earthquake (Uang et al. 1997). The two-dimensional model consisted of beams and columns modeled by nonlinear beam-column element, $2 \%$ strain hardening for the beams, steel section P-M interaction curve for columns, panel zones modeled as 


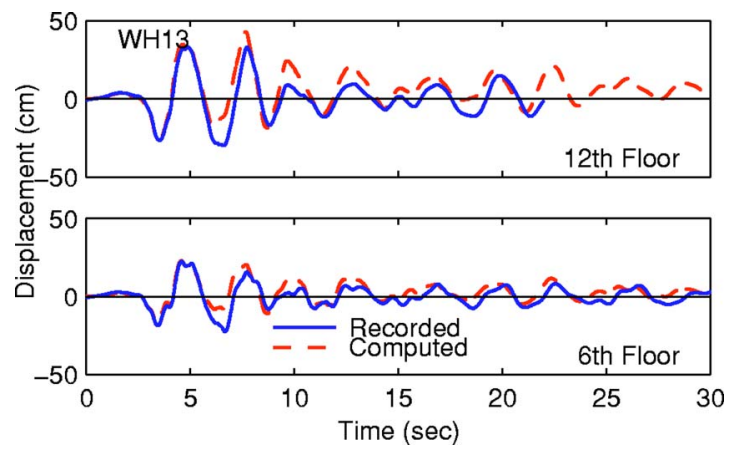

Figure 8. Comparison of displacements computed from analytical model with recorded displacements of the Woodland Hills 13-story building.

semi-rigid with connection element, Rayleigh damping of $7 \%$ for the first and third modes, and yield stress for steel members equal to $36 \mathrm{ksi}$. The two-dimensional model for this building is reasonable because of symmetric plan of this building.

The displacement response history of the analytical model was calculated using the north-south component of the motion recorded at the base during the 1994 Northridge earthquake. The comparison of displacements from the response history analysis with the recorded motions in the north-south direction at the center of the building, shown in Figure 8 , indicates a reasonable match between the two. This implies that the simple model used in this study is adequate in representing the recorded motions. It may be possible to further improve the accuracy of the model by using more "accurate" connection behavior. Note that the connection fracture could not be modeled due to lack of an appropriate element in the computer program DRAIN-2DX.

\section{SHERMAN OAKS 13-STORY BUILDING}

The computer model was developed for the exterior frame in the east-west direction for this building. The model was developed based on the structural plans and additional information available in an earlier study (JAMA 1973). The frame is modeled using beam-columns elements with centerline dimensions. Initial stiffness was equal to 0.5 and 0.7 times the gross cross-sectional stiffness for beams and columns, respectively. Rigid end offsets equal to $50 \%$ of the joint dimensions were assumed. The beams were modeled without P-M interaction, while P-M interaction relationship for reinforced concrete sections was used for the columns. The moment yield strengths were computed using moment-curvature analysis. The mass equal to one-third of the total building mass was assigned to this frame, and Rayleigh damping of $10 \%$ was assigned to the first and third mode of vibration.

The displacement response history of the analytical model was calculated using the east-west component of the motion recorded at the base during the 1994 Northridge earthquake. The comparison of displacements from the response history analysis with the recorded motions in the east-west direction at the center of the building, shown in 

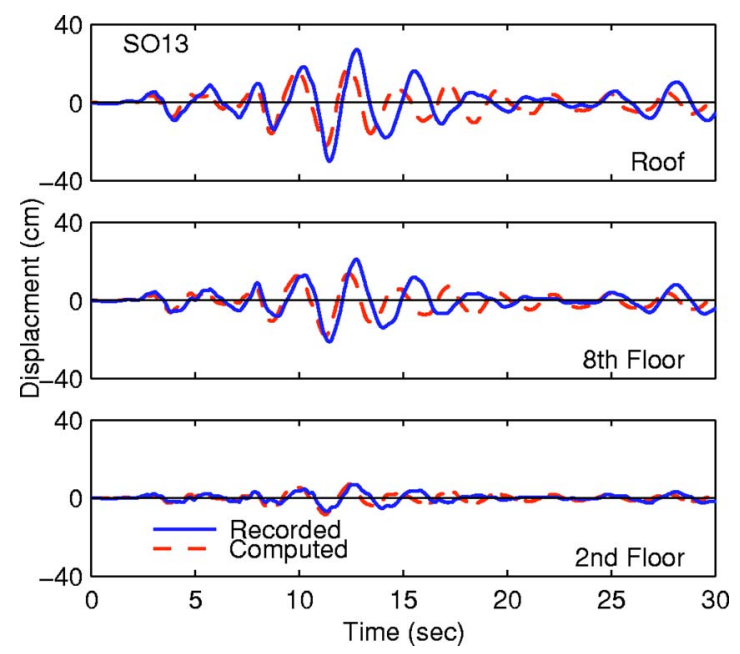

Figure 9. Comparison of displacements computed from analytical model with recorded displacements of the Sherman Oaks 13-story building.

Figure 9, indicates a reasonable match between the two. This implies that the simple model used in this study is reasonable in representing the recorded motions. As mentioned previously, for the Van Nuys building, it may be possible to further improve the accuracy of the model by using more appropriate force-deformation relationships.

\section{LOS ANGELES 19-STORY BUILDING}

The computer model was developed for braced frames in the north-south direction for this building based on the structural plans and additional information available in an earlier study (Hart 1973). The two-dimensional model consisted of columns modeled by nonlinear beam-column element with 3\% strain hardening and steel section P-M interaction relationship. The beams are modeled as truss elements with equal compressive and tensile strength and no compression buckling. The braces are also modeled with truss elements but with different tensile and compressive strengths; the tensile strength is specified as steel yield stress times the area of cross section, and the compressive strength is computed as the elastic buckling stress equal to $0.877 \pi^{2} E /(L / r)^{2}$ times the area of cross section. The damping was selected to be 3\% for the first and third modes. The expected yield stress for steel members equal to $46.8 \mathrm{ksi}$ is used. Each of the five braced frames (Figure 4) in the north-south direction was modeled and constrained to deform together to obtain a two-dimensional model for this building.

The displacement response history of the analytical model was calculated using the average of the accelerations recorded by channels 2 and 3 (Figure 4) in the north-south direction at the level D during the 1994 Northridge earthquake. The comparison of dis- 


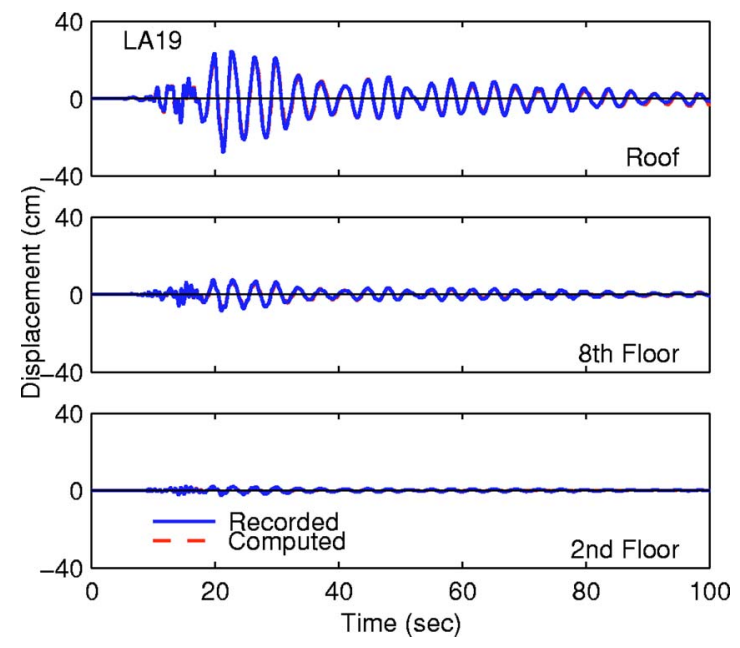

Figure 10. Comparison of displacements computed from the analytical model with recorded displacements of the Los Angeles 19-story building.

placements from the response history analysis with the recorded motions in the northsouth direction at the center of the building, shown in Figure 10, shows an excellent match between the two indicating adequacy of the model.

\section{NONLINEAR STATIC PROCEDURES}

\section{FEMA-356 NSP}

The Nonlinear Static Procedure (NSP) specified in the FEMA-356 (ASCE 2000) document may be used for any structure and any rehabilitation objective except for structures with significant higher mode effects. To determine if higher mode effects are present, two linear response spectrum analyses must be performed: (1) using sufficient modes to capture $90 \%$ of the total mass, and (2) using only the fundamental mode. If shear in any story from the first analysis exceeds $130 \%$ of the corresponding shear from the second analysis, the higher mode effects are deemed significant. In case the higher mode effects are present, the NSP analysis needs to be supplemented by the Linear Dynamic Procedure (LDP); acceptance criteria for the LDP are relaxed but remain unchanged for the NSP.

The FEMA-356 NSP requires development of a pushover curve, which is defined as the relationship between the base shear and lateral displacement of a control node, ranging between zero and $150 \%$ of the target displacement. The control node is located at the center of mass at the roof of a building. For buildings with a penthouse, the floor of the penthouse (not its roof) is regarded as the level of the control node. Gravity loads are applied prior to the lateral load analysis required to develop the pushover curve. 
The pushover curve is developed for at least two vertical distributions of lateral loads. The first pattern is selected from one of the following:

(1) Equivalent lateral force (ELF) distribution: $s_{j}^{*}=m_{j} h_{j}^{k}$ (the floor number $j$ $=1,2, \ldots \mathrm{N})$ where $s_{j}^{*}$ is the lateral force and $m_{j}$ the mass at $j$ th floor, $h_{j}$ is the height of the $j$ th floor above the base, and the exponent $k=1$ for fundamental period $T_{1} \leqslant 0.5 \mathrm{sec}, k=2$ for $T_{1} \geqslant 2.5 \mathrm{sec}$; and varies linearly in between.

(2) Fundamental mode distribution: $s_{j}^{*}=m_{j} \phi_{j 1}$ where $\phi_{j 1}$ is the fundamental mode shape component at the $j_{\text {th }}$ floor.

(3) RSA distribution: $s^{*}$ is defined by the lateral forces back-calculated from the story shears determined by linear response spectrum analysis of the structure including sufficient number of modes to capture $90 \%$ of the total mass.

The second pattern is selected from either "Uniform" distribution: $s_{j}^{*}=m_{j}$ in which $m_{j}$ is the mass and $s_{j}^{*}$ is the lateral force at $j$ th floor; or adaptive distribution that changes as the structure is displaced. This distribution should be modified from the original distribution by considering properties of the yielded structure.

The target displacement is computed from

$$
\delta_{t}=C_{0} C_{1} C_{2} C_{3} S_{a} \frac{T_{e}^{2}}{4 \pi^{2}} g
$$

where $T_{e}=$ Effective fundamental period of the building in the direction under consideration, $S_{a}=$ Response spectrum acceleration at the effective fundamental vibration period and damping ratio of the building under consideration and $g$ is the acceleration due to gravity, $C_{0}=$ Modification factor that relates the elastic response of an SDF system to the elastic displacement of the MDF building at the control node, $C_{1}=$ Modification factor that relates the maximum inelastic and elastic displacement of the SDF system, $C_{2}=$ Modification factor to represent the effects of pinched hysteretic shape, stiffness degradation, and strength deterioration, and $C_{3}=$ Modification factor to represent increased displacement due to P-delta effects.

The deformation/force demands in each structural element is computed at the target displacement and compared against acceptability criteria set forth in the FEMA-356 document. These criteria depend on the material (e.g., concrete, steel, etc.), type of member (e.g., beam, column, panel zones, connections, etc.), importance of the member (e.g., primary, or secondary) and the structural performance levels (e.g., immediate occupancy, life safety, collapse prevention).

The FEMA-356 NSP procedure contains several approximations. These include those in estimating the target displacement from Equation 3, and using the pushover curve to estimate the member demands imposed by the earthquake. In this investigation, the focus is primarily on the second source of approximation; the first approximation is a focus of numerous other investigations.

The target displacement for the FEMA-356 NSP is selected to be equal to that of the roof level recorded during the earthquake, as opposed to calculating it from Equation 3. The structure is pushed to this target displacement using the FEMA-356 lateral load pat- 
terns and floor displacements and interstory drifts are computed. These computed responses are then compared with the recorded motions. Such a comparison enables evaluation of the adequacy of various lateral load patterns in the FEMA-356 NSP, in particular, if the FEMA-356 NSP is able to capture the higher mode effects, which are likely to be present in the selected buildings.

\section{MPA PROCEDURE}

Following is a summary of the MPA procedure that has been developed to account for the higher mode effects (Chopra and Goel 2002, Goel and Chopra 2004):

1. Compute the natural frequencies, $\omega_{n}$ and modes, $\boldsymbol{\phi}_{n}$, for linearly elastic vibration of the building.

2. For the $n$th mode, develop the base shear-roof displacement, $V_{b n}-u_{r n}$, pushover curve for force distribution, $\mathbf{s}_{n}^{*}=\mathbf{m} \boldsymbol{\phi}_{n}$, where $\mathbf{m}$ is the mass matrix of the structure. Gravity loads, including those present on the interior (gravity) frames, are applied before the modal pushover analysis. The resulting P- $\Delta$ effects may lead to negative post-yielding stiffness in the pushover curve. Note the value of the lateral roof displacement due to gravity loads, $u_{r g}$.

3. Idealize the pushover curve as a bilinear curve. If the pushover curve exhibits negative post-yielding stiffness, the second stiffness (or post-yield stiffness) of the bilinear curve would be negative.

4. Convert the idealized $V_{b n}-u_{r n}$ pushover curve to the force-displacement, $F_{s n} / L_{n}-D_{n}$, relation for the $n$ th-"mode" inelastic SDF system by utilizing $F_{\text {sny }} / L_{n}=V_{b n y} / M_{n}^{*}$ and $D_{n y}=u_{r n y} / \Gamma_{n} \phi_{r n}$ in which $M_{n}^{*}$ is the effective modal mass, $\phi_{r n}$ is the value of $\phi_{n}$ at the roof, and $\Gamma_{n}=\phi_{n}^{T} \mathbf{m} 1 / \boldsymbol{\phi}_{n}^{T} \mathbf{m} \boldsymbol{\phi}_{n}$.

5. Compute the peak deformation $D_{n}$ of the nth-"mode" inelastic single-degree-offreedom (SDF) system defined by the force-deformation relation developed in Step 4 and damping ratio $\zeta_{n}$. The elastic vibration period of the system is $T_{n}$ $=2 \pi\left(L_{n} D_{n y} / F_{\text {sny }}\right)^{1 / 2}$. For an SDF system with known $T_{n}$ and $\zeta_{n}, D_{n}$ can be computed either by nonlinear RHA, from inelastic design spectrum, or by empirical equations for the ratio of deformations of inelastic and elastic systems (Chopra and Chintanapakdee 2004).

6. Calculate peak roof displacement $u_{r n}$ associated with the $n$ th-"mode" inelastic SDF system from $u_{r n}=\Gamma_{n} \phi_{r n} D_{n}$.

7. From the pushover database (Step 2), extract values of desired responses $r_{n+g}$ due to the combined effects of gravity and lateral loads at roof displacement equal to $u_{r n}+u_{r g}$.

8. Repeat Steps 3-7 for as many modes as required for sufficient accuracy.

9. Compute the dynamic response due to $n$th "mode": $r_{n}=r_{n+g}-r_{g}$, where $r_{g}$ is the contribution of gravity loads alone.

10. Determine the total response (demand) by combining gravity response and the peak "modal" responses using the SRSS (or CQC) rule: $r$ $\approx \max \left[r_{g} \pm\left(\Sigma_{n} r_{n}^{2}\right)^{1 / 2}\right]$.

Steps 3 to 6 of the MPA procedure described above are used to compute the peak roof displacement associated with the $n$ th-"mode" inelastic SDF system. However, these 
(a) Van Nuys

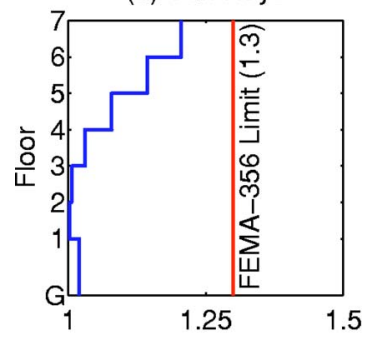

(c) Sherman Oaks

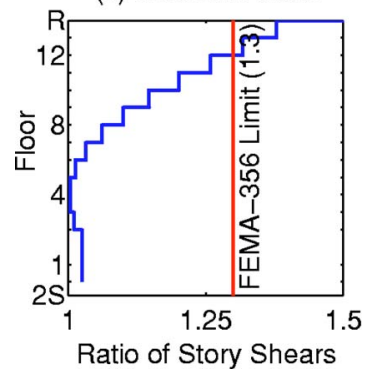

(b) Woodland Hills

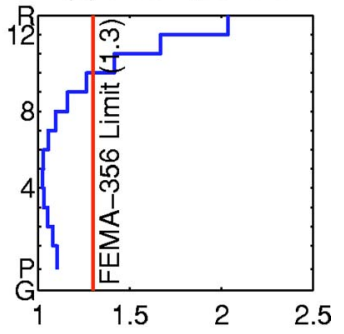

(d) Los Angeles

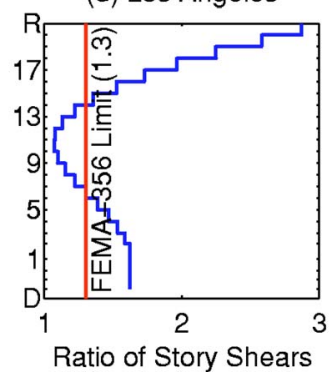

Figure 11. FEMA-356 check for presence of higher modes in the selected buildings.

steps are not necessary for analysis of a building for which recorded motions are available. The contribution of the $n$th "mode" to the total roof displacement, $u_{r n}$, can be computed from modal decomposition of recorded motion using Equation 2.

\section{FEMA-356 CHECK FOR HIGHER MODES}

The FEMA-356 criterion for checking presence of significant higher mode effects is applied to the four selected buildings. For this purpose, story shears are computed from two elastic modal analyses: (1) considering sufficient number of modes to capture at least $90 \%$ of the total mass, and (2) considering the fundamental mode only. For the Van Nuys building, three modes were sufficient to capture $90 \%$ of the total mass, whereas five modes were needed for the Woodland Hills, Sherman Oaks, and Los Angeles buildings. The ratio of the story shears from the two analyses is computed and compared with the limiting value of 1.3 specified in the FEMA-356 document. The results presented in Figure 11 lead to the following conclusions.

The ratio of story shears from 3-mode analysis and 1-mode analysis is less than the FEMA-356 limiting value of 1.3 throughout the height of the Van Nuys building (Figure 11a). Therefore, the FEMA-356 criterion indicates that higher mode effects should not be significant for this building. However, the displacement and drift profile histories during the ground shaking (Figures 5a and 6a) indicated presence of higher mode effects, especially in the story drifts. This apparent discrepancy will be further examined in the next section. 
The ratio of story shears from 5-mode analysis and 1-mode analysis exceeds the FEMA-356 limiting value of 1.3 in the upper stories of the Woodland Hills, Sherman Oaks, and Los Angeles buildings (Figures 11b-11d); for the Los Angeles building, this ratio exceeds the limiting value of 1.3 for the lower stories as well (Figure 11d). Clearly, these buildings are expected to respond significantly in higher modes. The displacement and drift profile histories of these buildings during the ground shaking (Figures 5 and 6) also indicated presence of higher mode effects, especially in the story drifts. Among these three buildings, the FEMA-356 criterion is barely exceeded in the upper two stories of the Sherman Oaks building (Figure 11c).

The results of Figure 11 indicate that the FEMA-356 NSP is expected to provide sufficiently accurate estimates of the seismic demands for the Van Nuys building and perhaps for the Sherman Oaks building; the FEMA-356 higher mode criterion is satisfied throughout the height of the first building (Figure 11a) and barely exceeded in the upper two stories of the second building (Figure 11c). However, the FEMA-356 NSP is not expected to give accurate seismic demands for the Woodland Hills and Los Angeles buildings because this criterion is significantly exceeded for these buildings (Figures $11 \mathrm{~b}$ and 11d). The results from the FEMA-356 NSP are included for these two buildings in this investigation to demonstrate the well-known limitation that the FEMA-356 NSP should not be used alone for buildings with significant higher mode effects.

\section{PUSHOVER CURVES FOR FEMA AND MODAL DISTRIBUTIONS}

The lateral force distributions corresponding to the four FEMA-356 NSP and the first three modes of the MPA procedure are used to generate pushover curves for the longitudinal frame on the south face of the Van Nuys building, the frame in the northsouth direction of the Woodland Hills building, the longitudinal frame in the east-west direction of the Sherman Oaks building, and the braced frames in the north-south direction of the Los Angeles buildings; first initiation of yielding in beams, columns, connections, or braces (buckling in compression) is also indicated on each pushover curve. These pushover curves lead to the following observations.

The characteristic - elastic stiffness, yield strength, and yield displacement — of the pushover curve depend on the lateral force distribution (Figure 12). The "Uniform" distribution generally leads to pushover curve with higher elastic stiffness, higher yield strength, and lower yield displacement compared to all other distributions. The ELF distribution, on the other hand, leads to pushover curve with lower elastic stiffness, lower yield strength, and higher yield displacement. The "Mode" 1 and RSA distribution give pushover curves that are bounded by the pushover curves due to "Uniform" and ELF distributions.

For the Van Nuys and Sherman Oaks buildings (Figures 12a and 12c), the "Mode" 1 and RSA pushover curves are essentially identical. For the Woodland Hills building (Figure 12b), the two curves are essentially identical up to the elastic limit. Thereafter, the strength is higher for the RSA distribution compared to the "Mode" 1 distribution. For the Los Angeles building (Figure 12d), the "Mode" 1 curve is essentially identical to the ELF curve. 

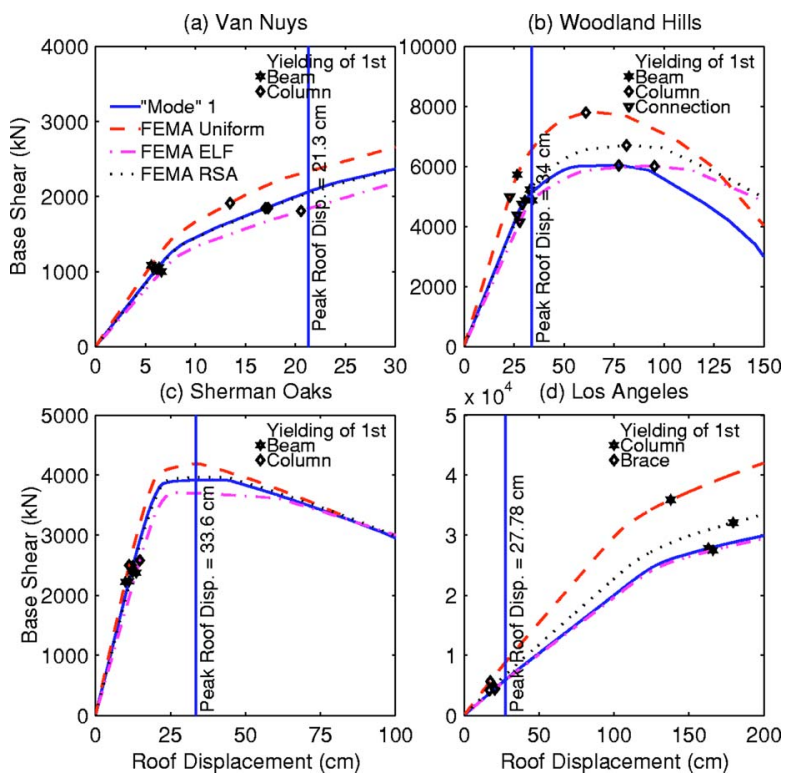

Figure 12. Pushover curves for the four FEMA-356 distributions.

The pushover curves for the Woodland Hills and Sherman Oaks buildings (Figures $12 \mathrm{~b}$ and 12c) exhibit significant degradation in lateral-load-carrying capacity at large roof displacements. The onset of the degradation depends on the lateral force distribution: the "Uniform" distribution induces the earliest, the ELF distribution the latest, and the "Mode" 1 and RSA distributions in between the "Uniform" and ELF distributions. The degradation in the lateral-load-carrying capacity occurs due to P-delta effects arising from the gravity loads. These effects may lead to negative slope of the pushover curve at large roof displacements, as apparent for the Woodland Hills and Sherman Oaks buildings (Figures $12 \mathrm{~b}$ and 12c).

In the Van Nuys building, the first yielding is initiated in the beams; the first yielding of columns occurs at much larger displacements (Figure 12a). The first yielding in the Woodland Hills building occurs in the connection followed soon after by the first yielding of the beam (Figure 12b). The columns start to yield at a much higher deformation level, followed immediately by rapid deterioration of the lateral-load-carrying capacity of the building. The first yielding in the Sherman Oaks building occurs in the beam, followed soon after by the first yielding of the column (Figure 12c). The yielding in the Los Angeles building initiates at very low deformation levels due to buckling of the compression braces (Figure 12d). The columns yield at much higher deformation level.

For the Van Nuys building, the expectation was that the first yielding would be initiated in the columns. This building has several shear-critical columns that would fail in shear-as observed during the 1994 Northridge earthquake-before developing their full flexural strength. This column behavior should prevent beam yielding because 

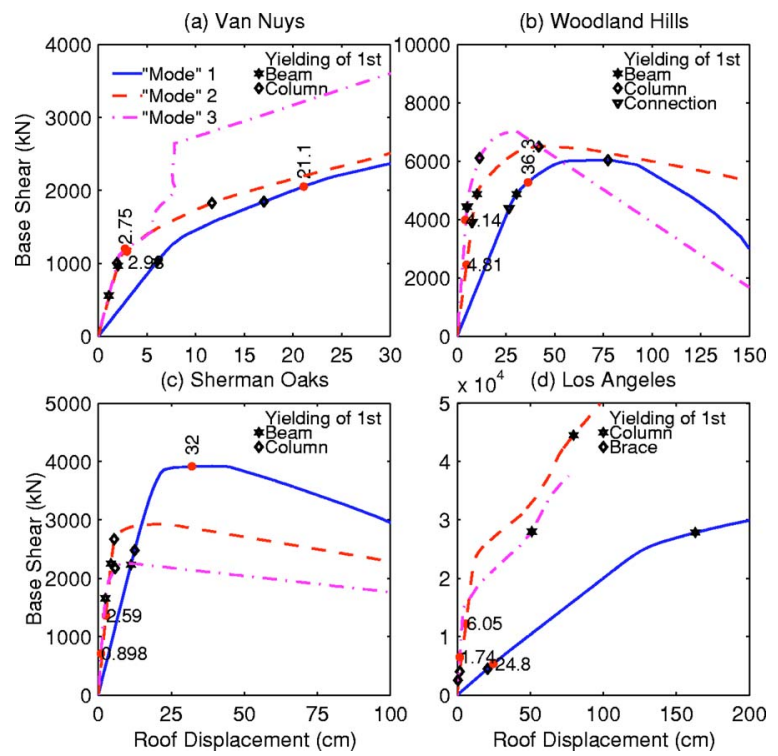

Figure 13. Pushover curves for the three modal distributions.

beams would not be able to develop their full flexural strengths. However, the analytical model used in this investigation did not include shear-critical behavior of columns due to lack of an appropriate element in the computer program DRAIN-2DX. As a result, the pushover analysis of the analytical model could not identify early yielding in columns and permitted yielding in beams (Figure 12a). However, the overall displacement response of the analytical model, with all these limitations, was reasonably close to that obtained from recorded motions (Figure 7).

The peak displacement recorded at the roof of each selected building during the 1994 Northridge earthquake is also shown in Figure 12. These results indicate that the Van Nuys and the Sherman Oaks buildings are deformed significantly beyond the elastic limit during the 1994 Northridge earthquake, as apparent from the peak roof displacement being much larger than the yield displacement (Figures 12a and 12c). The Woodland Hills building is deformed only slightly beyond the elastic limit, and the Los Angeles building responded essentially in the elastic range, except for buckling of a few braces, during the 1994 Northridge earthquake.

The "modal" pushover curves are shown in Figure 13. Included on each pushover curve is the peak value of the modal component of the roof displacement derived from the motions recorded during the 1994 Northridge earthquake; the modal component is computed from standard modal decomposition procedure described previously (Equation 2). For example, the peak values of the first, second, and third mode contribution to the total roof displacement were computed to be $21.1 \mathrm{~cm}, 2.93 \mathrm{~cm}$, and $2.75 \mathrm{~cm}$, respec- 
tively, from the roof motions of the Van Nuys building recorded the 1994 Northridge earthquake. These values are shown on each of the three modal pushover curves of this building in Figure 13a.

The "modal" pushover curves show that the Van Nuys building (Figure 13a) experienced significant yielding in the first "mode." The building is deformed nearly to the elastic limit of the pushover curve in the second and third modes. However, yielding in these modes has been initiated in some beams and columns. While the Woodland Hills and Sherman Oaks buildings are deformed beyond the elastic limit only in the first mode (Figures $13 \mathrm{~b}$ and 13c), these buildings remain elastic in the higher modes with the modal contribution of associated modes to the roof displacement during the 1994 Northridge earthquake being smaller than that required to induce yielding in any element. The Los Angeles building remains essentially elastic in all modes (Figure 13d). However, the peak deformation may be slightly larger than that required for first buckling in the compression braces for all modes.

As noted previously, none of the selected buildings responded beyond the elastic limit in modes higher than the fundamental mode. For such buildings, the Modified Modal Pushover Analysis (MMPA), wherein the response contributions of the modes higher than the fundamental mode are computed by assuming the building to be linearly elastic, may be used to estimate the seismic demands (Chopra et al. 2004). The MMPA procedure is an attractive alternative to the MPA procedure for these buildings because of reduced computational efforts; the pushover curves for higher modes are not needed in the MMPA procedure.

The pushover results presented so far also show that while Van Nuys, Woodland Hills, and Sherman Oaks buildings were deformed beyond the elastic limit during the 1994 Northridge earthquake, the Los Angeles building remained essentially elastic, except for buckling of a few braces, during this earthquake. Therefore, FEMA-356 NSP procedures - developed for estimating seismic demands in buildings deformed beyond the elastic limits - may not be strictly applicable for the Los Angeles building. However, the MPA procedure, which becomes equivalent to the standard Response Spectrum Analysis (RSA) procedure for buildings responding in the linear elastic range (Chopra and Goel 2002), can still be used to estimate the seismic demands of the Los Angeles building. For this reason, this building is still included in this investigation. While it is recognized that results from the FEMA-356 NSP procedure may not be strictly valid for this building, these results are included for comparison purposes.

\section{EVALUATION OF NONLINEAR STATIC PROCEDURES}

The FEMA-356 NSP and MPA procedures are evaluated in this section by using recorded motions of selected buildings. For this purpose, the floor displacements and story drifts from the four FEMA-356 analyses and MPA procedure are compared with the "derived" values from the recorded motions. The target roof displacement in the FEMA-356 analyses was selected to be that "derived" from the motions recorded at the roof. Similarly, the $n$ th-"mode" component of the roof displacement, $u_{r n}$, required in the MPA procedure was taken to be the value obtained from the $n$th "modal" decomposition of the 

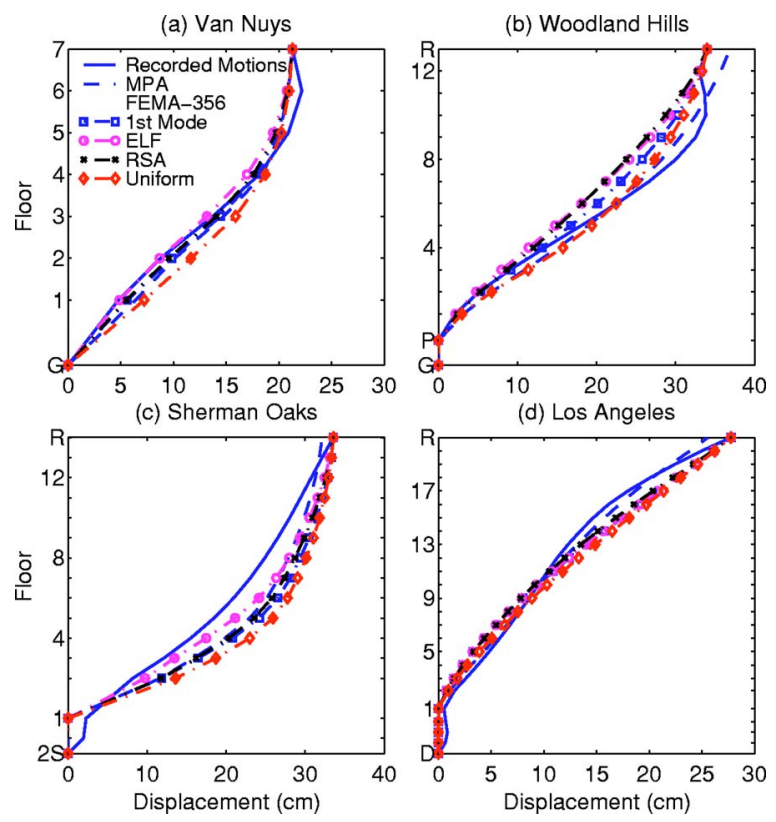

Figure 14. Comparison of displacements from recorded motions, MPA procedure, and FEMA356 NSP for the four distributions.

recorded motions. Also compared are the modal components of floor displacements and story drifts from MPA procedure with the "modal" components obtained from modal decomposition of recorded motions. It is useful to emphasize again that two-dimensional models have been used in this investigation and the computed and recorded motions at the center of the selected buildings are examined in this section. Although the FEMA356 criterion for higher mode effects is significantly exceeded for two of the four selected buildings, results from the FEMA-356 NSP are included because such analyses are permitted in conjunction with the LDP analysis.

The results presented for the floor displacements (Figure 14) show that all procedures - the four FEMA-356 distributions and the MPA-lead to floor displacements that are essentially similar to those "derived" from recorded motions with some minor discrepancies. Note that displacements at the roof level from the FEMA-356 analyses and the recorded motions are the same because the target roof displacement in the FEMA-356 analyses was selected to be the roof displacement during the ground motion. The displacements are slightly overestimated at lower floor and underestimated slightly at upper floors for the Van Nuys building (Figure 14a); underestimated slightly in middle few floors of the Woodland Hills building (Figure 14b); slightly overestimated at most floors of the Sherman Oaks building (Figure 14c); and slightly underestimated at lower floors and overestimated at upper floors of the Los Angeles building (Figure 14d) by the NSP procedures. 

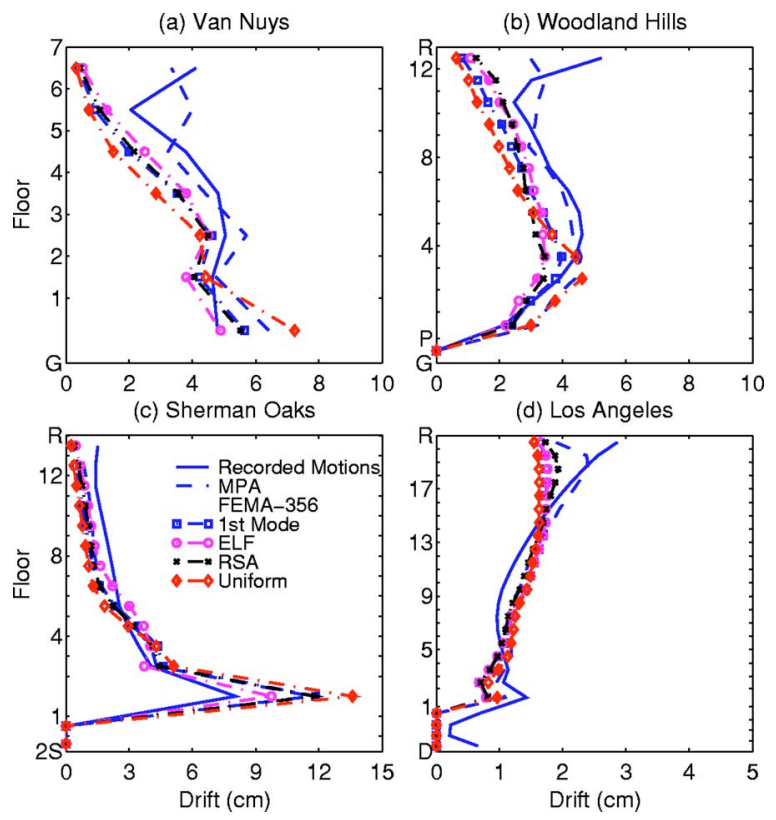

Figure 15. Comparison of story drifts from recorded motions, MPA procedure, and four FEMA-356 NSP for the four distributions.

Although two of the four selected buildings significantly exceeded the FEMA-356 criterion for higher mode effects (Figure 11), the FEMA-356 NSP, which is applicable for buildings responding primarily in the fundamental mode, provided reasonable estimate of the floor displacement. Furthermore, the MPA procedure, which is designed to capture higher mode effects, did not lead to displacements much different from the FEMA-356 NSP. This is the case because the fundamental mode is known to dominate floor displacements (Chopra 2001); higher mode contributions are typically very small for floor displacements.

The comparison of story drifts from the FEMA-356 analyses and the recorded motions (Figure 15) show that the FEMA-356 force distributions lead to gross underestimation of drifts in the upper stories of all of the four selected buildings. Among the four FEMA-356 distributions, the "Uniform" force distribution almost always leads to the worst estimates of story drifts (Figure 15). This distribution leads to underestimation of the top-story drift by more than $90 \%$ for the Van Nuys building, by about $67 \%$ for the Woodland Hills building, by more than $80 \%$ for the Sherman Oaks building, and by more than $40 \%$ for the Los Angeles building (Table 2). Therefore, the usefulness of the "Uniform" distribution in the FEMA-356 NSP should be re-examined. A similar observation was also made in an earlier study based on the analytical response of six buildings with steel moment-resisting frames (Goel and Chopra 2004). 
Table 2. Difference in top-story drifts from NSP using FEMA-356 "Uniform" distribution and recorded motions

\begin{tabular}{lccc}
\hline \hline Building & FEMA-356 $(\mathrm{cm})$ & $\begin{array}{c}\text { Drifts } \\
\text { Recorded }(\mathrm{cm})\end{array}$ & Difference (\%) \\
\hline Van Nuys & 0.32 & 4.11 & -92 \\
Woodland Hills & 1.02 & 3.01 & -67 \\
Sherman Oaks & 0.24 & 1.51 & -84 \\
Los Angeles & 1.55 & 2.86 & -46 \\
\hline \hline
\end{tabular}

The FEMA-356 NSP also led to significant overestimation of the drift in the lower stories of the Van Nuys and Sherman Oaks building (Figures 15a and 15c). As noted previously, the "Uniform" distribution led to the worst results. For example, this distribution led to overestimation of the drift in the first story by about $50 \%$ for the Van Nuys building, and by nearly $70 \%$ for the Sherman Oaks building (Table 3).

The presented results for story drifts of the Van Nuys building (Figure 15a) also demonstrate another serious limitation of the FEMA-356 NSP. The higher mode effects for this building were deemed not to be significant based on the FEMA-356 criterion (Figure 11a). Therefore, expectation was that the FEMA-356 NSP would lead to reasonable estimates of drifts throughout the building height. Yet the drifts are significantly underestimated in upper stories by the FEMA-356 NSP (Figure 15a). Since the larger drifts in upper stories tend to occur due to higher modes, it appears that higher mode effects were significant for this building and the FEMA-356 criterion apparently failed to identify these effects. This indicates that the FEMA-356 criterion for significant higher mode effects should be reexamined.

The inability of the FEMA-356 NSP in accurately estimating the drifts in upper stories of the Woodland Hills and Los Angeles buildings - the two buildings for which the FEMA-356 criterion for higher modes is significantly exceeded (Figures $11 \mathrm{~b}$ and 11d) validates the well-known limitation that the FEMA-356 NSP alone is not applicable for buildings with significant higher mode effects. The authors of FEMA-356 clearly acknowledged this limitation of the FEMA-356 NSP procedure and required that the results of the NSP analyses be supplemented by the results of the LDP analysis for such buildings.

Table 3. Difference in first-story drifts from NSP using FEMA-356 "Uniform" distribution and recorded motions

\begin{tabular}{lccc}
\hline \hline Building & FEMA-356 (cm) & $\begin{array}{c}\text { Drifts } \\
\text { Recorded }(\mathrm{cm})\end{array}$ & Difference (\%) \\
\hline Van Nuys & 7.23 & 4.80 & +50 \\
Sherman Oaks & 13.6 & 8.05 & +69 \\
\hline \hline
\end{tabular}


The MPA procedure for three of the four selected buildings-Van Nuys, Woodland Hills, and Los Angeles - provides estimates of story drifts that are much closer, with a few exceptions, to those from the recorded motions compared to the estimates from the FEMA-356 NSP (Figures 15a, 15b, and 15d). Since response histories of these buildings presented earlier (Figure 6) showed presence of significant higher mode effects, the results of Figure 15 lead to the conclusion that the MPA procedure is, in general, able to capture these effects. This suggests that the MPA procedure may be used for NSP analysis of buildings with significant higher mode effects without any supplemental analysis as required in the FEMA-356 NSP for such buildings.

It must be noted that significant discrepancies may exist between results of the MPA and recorded motions at a few locations, such as drift in the $6^{\text {th }}$ story of the Van Nuys building (Figure 15a), and top stories of Woodland Hills and Los Angeles buildings (Figures $15 \mathrm{~b}$ and $15 \mathrm{~d}$ ). The reasons behind this discrepancy are examined later in this section.

For the Sherman Oaks building, the MPA procedure provides estimates of the story drifts slightly better than those from the FEMA-356 NSP (Figure 15c). Although not apparent from Figure $15 \mathrm{c}$, the overestimation of drifts in lower stories and underestimation of drifts in upper stories from the MPA procedure is smaller compared to the FEMA-356 NSP. Yet the results from the MPA procedure are significantly different compared to those from the recorded motions for this building.

The results presented for story drifts of the Sherman Oaks building indicate that the behavior of this building is dominated by the effects of a "soft" first story. A large concentration of drift occurs in the first story (Figure 15c) both in results from recorded motions as well as FEMA-356 and MPA analyses; drifts in upper stories are only a small fraction of the drift in the first story. For such a building, where "soft" story effects dominate, the FEMA-356 NSP and MPA analyses both failed to provide reasonable estimate of story drifts: these procedures overestimate the drifts in the first story and underestimate them in the upper stories.

As noted previously, while the estimates of story drifts from the MPA procedure are better compared to the FEMA-356 NSP, significant differences may exist at a few locations. In order to understand the source of this discrepancy, peak displacement and drifts in each mode of the MPA procedure are compared with those obtained from modal decomposition of recorded motions (Figures 16 and 17). This comparison shows that the match between the two is reasonably good. Therefore, the prime source of discrepancy appears to be from modal combination procedure. The modal combination rule was found to be deficient in an earlier study (Goel and Chopra 2004), even for elastic buildings.

A fraction of the errors in the modal combination may be attributed to application of the modal combination rule, which is strictly valid for elastic buildings, for buildings responding beyond the elastic range. However, this fraction has been found to be small in an earlier study where errors in the MPA results of elastic and inelastic systems were compared (Goel and Chopra 2004). 
(a) Van Nuys
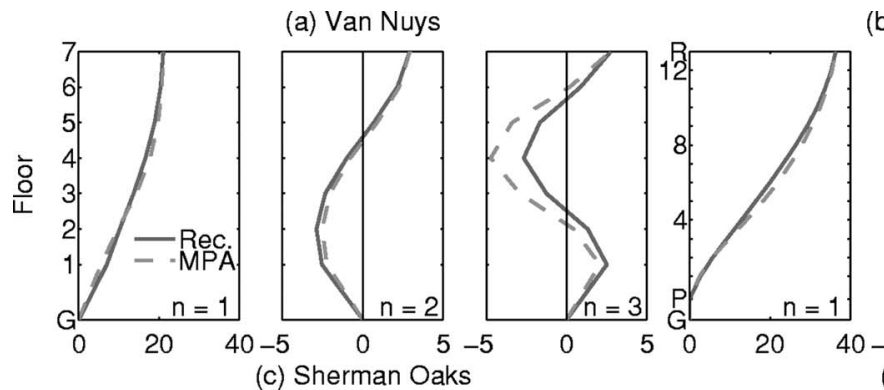

(b) Woodland Hills
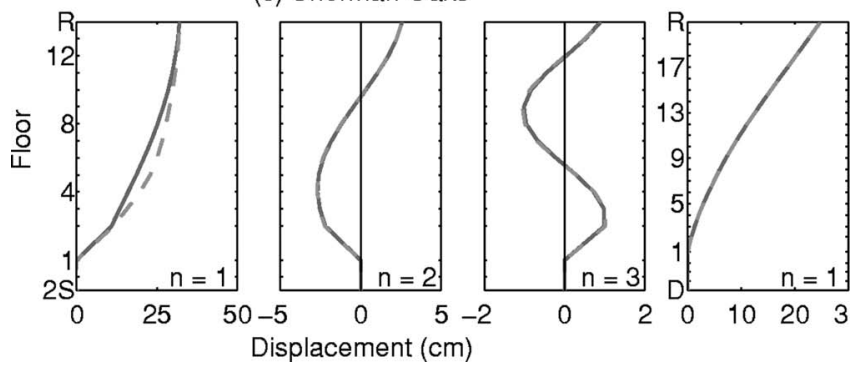

(d) Los Angeles
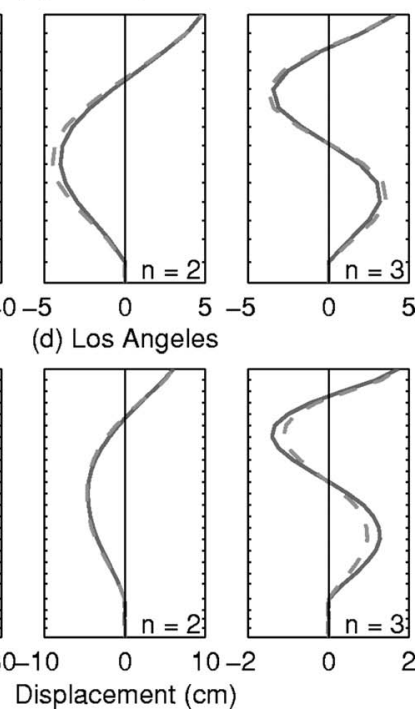

Figure 16. Comparison of displacements from MPA procedure with results derived from modal decomposition of recorded motions for the first three modes $(n=1,2$, and 3$)$.

(a) Van Nuys
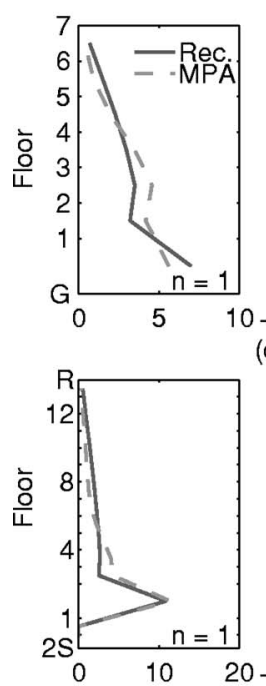
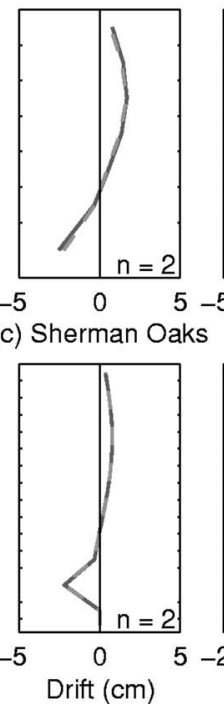

(b) Woodland Hills

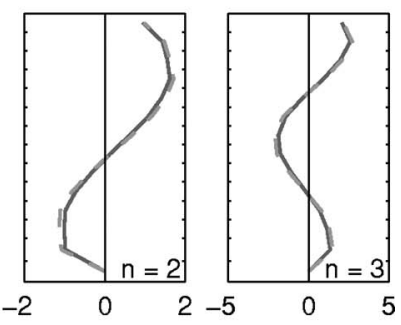

(d) Los Angeles

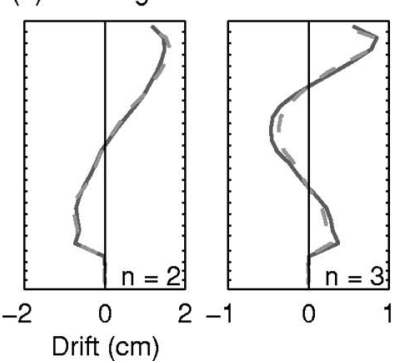

Figure 17. Comparison of story drifts from MPA procedure with results derived from modal decomposition of recorded motions for the first three modes $(n=1,2$, and 3$)$. 
The error in large part appears to be due to application of the modal combination rule for peak responses of a single ground motion. Note that the modal combination rules are based on random vibration theory and the combined peak response should be interpreted as the mean of the peak values of response to an ensemble of earthquake excitations. Thus the modal combination rules are intended for use when the excitation is characterized by a smooth response (or design) spectrum. Although modal combination rules can also approximate the peak response to a single ground motion characterized by a jagged response spectrum, the errors are expected to be much larger in some cases, as noted in this investigation.

It is useful to note that while the total drifts in the first story of the Sherman Oaks building is significantly overestimated by the MPA procedure (Figure 15c), the modeby-mode match between the recorded motions and the MPA procedure is excellent even for this building (Figure 17c). Furthermore, each "modal" analysis in the MPA procedure is able to capture the "soft" story effects, as apparent from the concentration of drifts in the first story of this building in results for each mode (Figure 17c). Therefore, failure of the MPA procedure in accurately estimating combined response for this building also appears to be due to limitations of the modal combination procedure when applied to a single ground motion.

\section{CONCLUSIONS}

This research investigation evaluated the FEMA-356 NSP and the MPA procedures using four buildings reported to be damaged and whose motions were recorded during the 1994 Northridge earthquake. Two-dimensional analytical models of these buildings were developed using computer program DRAIN-2DX and calibrated against information from the recorded motions. These models were analyzed using the FEMA-356 NSP and the MPA procedures.

The pushover curves for the four distributions-"Uniform," ELF, RSA, and first "Mode"-in the FEMA-356 NSP and for the first three modal distributions in the MPA procedure were generated for each of the selected buildings. These pushover curves led to the following conclusions.

- The characteristic - elastic stiffness, yield strength, and yield displacement - of the pushover curve depend on the FEMA-356 lateral force distribution. The "Uniform" distribution generally leads to pushover curve with higher elastic stiffness, higher yield strength, and lower yield displacement compared to all other distributions; the ELF distribution leads to pushover curve with lower elastic stiffness, lower yield strength, and higher yield displacement; and the "Mode" 1 and RSA distribution pushover curves are bounded by the pushover curves due to "Uniform" and ELF distributions.

- The pushover curves for the Woodland Hills and Sherman Oaks buildings exhibit significant degradation in lateral-load-carrying capacity at larger roof displacements due to P-delta effects arising from the gravity loads. Among the four FEMA-356 distributions, the "Uniform" distribution induces the earliest degradation in the lateral-load-carrying capacity 
- The Van Nuys and the Sherman Oaks buildings are deformed significantly beyond the elastic limit, the Woodland Hills building is deformed only slightly beyond the elastic limit, and the Los Angeles building responded essentially in the elastic range, except for buckling of a few braces, during the 1994 Northridge earthquake.

- Three of the four selected buildings - Van Nuys, Woodland Hills, and Sherman Oaks - are deformed beyond the elastic limit only in the first mode whereas the Los Angeles building remained elastic in all modes during the 1994 Northridge earthquake.

The estimates of the floor displacements and story drifts were computed from the FEMA-356 NSP and the MPA procedures. These estimates were compared against the values "derived" from the recorded motions of the selected buildings during the 1994 Northridge earthquake. This comparison led to the following conclusions:

- All procedures - the four FEMA-356 distributions and the MPA-lead to floor displacements that are essentially similar to those "derived" from recorded motions. This is the case because the fundamental mode is known to dominate floor displacements with very small contributions from higher modes.

- The FEMA-356 NSP led to gross underestimation of drifts in the upper stories of all four selected buildings and significant overestimation of drifts in the lower stories of two of the four buildings.

- The presented results confirm the well-known limitation that the FEMA-356 NSP alone is not applicable to buildings with significant higher mode effects. The authors of FEMA-356 clearly acknowledge this limitation of the FEMA-356 NSP and required supplemental LDP analysis for such buildings.

- Among the four FEMA-356 distributions, the "Uniform" force distribution leads to the most excessive underestimation in the upper stories and overestimation in the lower stories. The underestimation in the upper stories ranges from $90 \%$ for the Van Nuys building to about $40 \%$ for the Los Angeles building, and overestimation in the lower stories by about $50 \%$ to $70 \%$ occurred for Van Nuys and Sherman Oaks buildings, respectively. Therefore, the usefulness of this distribution in the FEMA-356 NSP should be re-examined. However, it must be noted that this conclusion is based on three moment-resisting frame buildings and one braced-frame building.

- The FEMA-356 NSP is expected to provide reasonable estimate of the response if the higher mode effects are deemed not to be significant based on the FEMA356 criterion. Although the FEMA-356 criterion is clearly satisfied for the Van Nuys building and nearly satisfied for the Sherman Oaks building, the drifts in upper stories are still significantly underestimated, indicating the need to reexamine the FEMA-356 criterion for evaluating significant higher mode effects.

- The MPA procedure provides estimates of drifts that are much closer to those from the recorded motions compared to those from the FEMA-356 NSP. Furthermore, the MPA procedure is able to account for the higher mode effects. This suggests that the MPA procedure may be used to obtain reasonable estimates of seismic demands of buildings with significant higher mode effects without any 
supplemental analysis as required in the FEMA-356 NSP.

- The "soft" first-story effects were dominant in the Sherman Oaks building. For this building, both the MPA and the FEMA-356 NSP failed to provide accurate estimates of story drifts.

Large discrepancy in drift estimates from the MPA procedure and the recorded motions was found at a few locations. This discrepancy is due to application of the modal combination procedure to results from single ground motion. The modal combination rules are based on random vibration theory and the combined peak response should be interpreted as the mean of the peak values of response to an ensemble of earthquake excitations. Thus the modal combination rules are intended for use when the excitation is characterized by a smooth response (or design) spectrum. Applied to the peak response to a single ground motion characterized by a jagged response spectrum, the errors are expected to be much larger in some cases, as noted in this investigation.

\section{ACKNOWLEDGMENTS}

This research investigation is supported by the California Department of Conservation, California Geological Survey, Strong Motion Instrumentation Program (SMIP) through Contract No. 1001-762. This support is gratefully acknowledged.

The author is grateful to Dr. Moh Huang and Mr. David Whitesel of SMIP for providing the recorded motions and structural plans of the selected buildings. Also acknowledged is the assistance provided by Dr. Abe Lynn of Cal Poly, San Luis Obispo, and Dr. Kent Yu of Degenkolb Engineers; the analytical model for the Van Nuys and Woodland Hills buildings were generated from the information provided by Dr. Lynn and Dr. Yu, respectively. This research investigation also benefited significantly from discussions with Prof. Anil Chopra of University of California at Berkeley, and members of the Strong Motion Instrumentation Advisory Committee (SMIAC). The useful feedback from anonymous reviewers of this paper is also gratefully acknowledged.

\section{REFERENCES}

American Society of Civil Engineers (ASCE), 2000. Prestandard and Commentary for the Seismic Rehabilitation of Buildings, prepared for the SAC Joint Venture, published by the Federal Emergency Management Agency, FEMA-356, Washington, D.C.

Applied Technology Council (ATC) 1996. Seismic Evaluation and Retrofit of Concrete Buildings, Report No. ATC-40, Redwood City, CA.

Applied Technology Council (ATC), 1997a. NEHRP Guidelines for the Seismic Rehabilitation of Buildings, prepared for the Building Seismic Safety Council, published by the Federal Emergency Management Agency, FEMA-273, Washington, D.C.

Applied Technology Council (ATC), 1997b. Commentary on the Guidelines for the Seismic Rehabilitation of Buildings, prepared for the Building Seismic Safety Council, published by the Federal Emergency Management Agency, FEMA-274, Washington, D.C.

Bracci, J. M., Kunnath, S. K., and Reinhorn, A. M., 1997. Seismic performance and retrofit evaluation for reinforced concrete structures, J. Struct. Eng. 123 (1), 3-10. 
Browning, J., Li, Y. R., Lynn, A. C., and Moehle, J. P., 2000. Performance assessment for a reinforced concrete frame building, Earthquake Spectra 16 (3), 541-555.

Chopra, A. K., 2001. Dynamics of Structures: Theory and Application to Earthquake Engineering, Prentice Hall, Englewood Cliffs, New Jersey.

Chopra, A. K., and Chintanapakdee, C., 2004. Inelastic deformation ratios for design and evaluations of structures: Single-degree-of-freedom bilinear systems, J. Struct. Eng. 130 (9), 1309-1319.

Chopra, A. K., and Goel, R. K., 2002. A modal pushover analysis procedure for estimating seismic demands for buildings, Earthquake Eng. Struct. Dyn. 31 (3), 561-582.

Chopra, A. K., Goel, R. K. and Chintanapakdee, C., 2004. Evaluation of a modified MPA procedure assuming higher modes as elastic to estimate seismic demands, Earthquake Spectra 20 (3), 757-778.

Darragh, R. B., Cao, T., Graizer, V., Shakal, A., and Huang, M., 1994. Los Angeles CodeInstrumented Building Records from the Northridge, California Earthquake of January 17, 1994: Processed Release No. 1, Report No. OSMS 94-17, Strong Motion Instrumentation Program, CDMG, Sacramento, CA.

De la Llera, J. C., and Chopra, A. K., 1998. Evaluation of Seismic Code Provisions Using Strong-Motion Building Records from the 1994 Northridge Earthquake, Report No. UCB/ EERC-97/16, Earthquake Engineering Research Center, University of California, Berkeley, CA.

Elnashai, A. S., 2001. Advanced inelastic static (pushover) analysis for earthquake applications, Struct. Eng. Mech. 12 (1), 51-69.

Fajfar, P., and Gaspersic, P., 1996. The N2 method for the seismic damage analysis of RC buildings, Earthquake Eng. Struct. Dyn. 25 (1), 31-46.

Goel, R. K., 2003. Evaluation of Nonlinear Static Procedures Using Strong-Motion Records of Buildings, CSMIP Data Utilization Report, California Strong Motion Instrumentation Program, California Geological Survey, Sacramento, CA.

Goel, R. K., and Chopra, A. K., 2004. Evaluation of modal and FEMA pushover analyses: SAC buildings, Earthquake Spectra 20 (1), 225-254.

Goel, R. K., Lynn, A. C., May, V. V., Rihal, S. S., and Weggel, D., 2000. Evaluating current procedures and modeling for seismic performance of reinforced concrete buildings, Proceedings of 12th World Conference on Earthquake Engineering, Auckland, New Zealand, Paper No. 2060.

Gupta, A., and Krawinkler, H., 1999. Seismic Demands for Performance Evaluation of Steel Moment Resisting Frame Structures (SAC Task 5.4.3), Report No. 132, John A. Blume Earthquake Engineering Center, Stanford, CA.

Gupta, B., and Kunnath, S. K., 2000. Adaptive spectra-based pushover procedure for seismic evaluation of structures, Earthquake Spectra 16 (2), 367-392.

Hart, G., 1973. 1901 Avenue of the Stars Building, San Fernando, California, Earthquake of February 9, 1971, edited by N. A. Benfer and J. L. Coffman, NOAA Special Report, U.S. Department of Commerce, National Oceanic and Atmospheric Administration, pp. 597-607.

Islam, M. S., Gupta, B., and Kunnath, S. K., 1998. A critical review of state-of-art analytical tools and acceptance criterion in light of observed response of an instrumented nonductile concrete frame building, Proceedings of 6th U.S. National Conference on Earthquake Engineering, Seattle, Wash. 
John A. Martin \& Associates (JAMA), 1973. High-rise buildings - Not instrumented Union Bank, San Fernando, California, Earthquake of February 9, 1971, edited by N. A. Benfer and J. L. Coffman, NOAA Special Report, U.S. Department of Commerce, National Oceanic and Atmospheric Administration, pp. 629-638.

Krawinkler, H., and Seneviratna, G., 1998. Pros and cons of a pushover analysis of seismic performance evaluation, Eng. Struct. 20 (4-6), 452-464.

Kunnath, S. K., and Gupta, B., 2000. Validity of deformation demand estimates using nonlinear static procedures, Proceedings of U.S.-Japan Workshop on Performance-Based Engineering for Reinforced Concrete Building Structures, Sapporo, Hokkaido, Japan.

Li, R., and Jirsa, J. O., 1998. Nonlinear analysis of an instrumented structure damaged in the 1994 Northridge earthquake, Earthquake Spectra 14 (2), 265-283.

Maison, B., and Bonowitz, D., 1999. How safe are pre-Northridge WSMFs? A case study of the SAC Los Angeles nine-story building, Earthquake Spectra 15 (4), 765-789.

Matsumori, T., Otani, S., Shinohara, H., and Kabeyasawa, T., 1999. Earthquake member deformation demands in reinforced concrete frame structures, Proceedings of U.S. Japan Workshop on Performance-Based Earthquake Engineering Methodology for RC Building Structures, Maui, Hawaii, pp. 79-94.

Naeim, F., 1997. Performance of Extensively Instrumented Buildings During the January 17, 1994 Northridge Earthquake: An Interactive Information System, Report No. 97-7530.68, John A. Martin \& Associates, Los Angeles, CA.

Naeim, F., 1998. Performance of 20 extensively instrumented buildings during the 1994 Northridge earthquake, Struct. Des. Tall Build. 7 (3), 179-194.

Naeim, F., 2000. Learning from structural and nonstructural seismic performance of 20 extensively instrumented buildings, Proceedings of 12th World Conference on Earthquake Engineering, Auckland, New Zealand, Paper No. 0217.

Paret, T. F., Sasaki, K. K., Eilbeck, D. H., and Freeman, S. A., 1996. Approximate inelastic procedures to identify failure mechanisms from higher mode effects, Proceedings of 11th World Conference on Earthquake Engineering, Acapulco, Mexico, Paper No. 966.

Prakash, V., Powell, G. H., and Campbell, S., 1993. DRAIN-2DX Base Program Description and User Guide, Version 1.10, Report No. UCB/SEMM-93-17, Department of Civil Engineering, University of California, Berkeley, CA.

Reinhorn, A. M., 1997. Inelastic Analysis Techniques in Seismic Evaluations, Seismic Design Methodologies for the Next Generation of Codes, edited by P. Fajfar and H. Krawinkler, Balkema, Rotterdam, pp. 277-287.

Sasaki, K. K., Freeman, S. A., and Paret, T. F., 1998. Multimode Pushover Procedure (MMP) - A method to identify the effects of higher modes in a pushover analysis, Proceedings of 6th U.S. National Conference on Earthquake Engineering, Seattle, Wash.

Shakal, A. F., Huang, M., and Darragh, R. B., 1994. Some implications of strong-motion records from the 1994 Northridge earthquake, Proceedings of SMIP94 Seminar on Utilization of Strong-Motion Data, Strong Motion Instrumentation Program, CDMG, Sacramento, Calif., pp. 1-20.

Skokan, M. J., and Hart, G. C., 2000. Reliability of nonlinear static methods for the seismic performance prediction of steel frame buildings, Proceedings of 12th World Conference on Earthquake Engineering, Auckland, New Zealand, Paper No. 1972. 
Uang, C. M., Yu, Q. S., Sadre, A., Youssef, N., and Vinkler, J., 1997. Seismic response of an instrumented 13-story steel frame building damaged in the 1994 Northridge earthquake, Earthquake Spectra 13 (1), 131-149.

U.S. Army, 1986. Seismic Design Guidelines for Essential Buildings, Departments of the Army (TM 5-809-10-1), Navy (NAVFAC P355.1), and the Air Force (AFM 88-3, Chapter 13, Section A), Washington, D.C. 